\title{
Simulation of Bifurcation in Brain Illness/ Remediation. Enzyme Reactions of the Neurocycle
}

\author{
Ibrahim Mustafa ${ }^{1,2}$, Asmaa Awad ${ }^{1}$, Elkamel $\mathbf{A}^{1}$ and Said Elnashaie ${ }^{3 *}$ \\ ${ }^{1}$ Department of Chemical Engineering, Waterloo University, Canada \\ ${ }^{2}$ Department of Biomedical Engineering, Helwan University, Egypt \\ ${ }^{3}$ Department of Chemical and Biological Engineering, University of British Columbia (UBC), Canada
}

*Corresponding author: Said Elnashaie, Department of Chemical and Biological

Engineering, University of British Columbia (UBC), Vancouver, Canada.

Received Date: November 06, 2019

Published Date: December 06, 2019

\section{Abstract}

Enzymes-Reactions Model is used to study: dynamics, bifurcation, and chaos of the acetylcholine neurocycle (ACNC). The effects of feed choline concentrations, Acetylcholinesterase (AChE) activity as bifurcation parameters are studied. It was found that feed choline concentrations are important and have direct effect on ACNC through certain important range of parameters. Detailed bifurcation analysis is carried out in order to uncover important features of the system, such as static/dynamic bifurcation and chaos. These findings are related to the real phenomena occurring in the neurons, like periodic stimulation of neural cells and non-regular functioning of acetylcholine receptors. Results are compared to the results of physiological experiments and other published models. As there is strong evidence that cholinergic brain diseases like Alzheimer's disease (AD) and Parkinson's disease (PD) are related to the concentration of acetylcholine, the present findings are useful for uncovering some of the characteristics of these illnesses/remediation.

Keywords: Acetylcholinesterase; Acetylcholine; Choline; Acetate; Parkinson's disease (PD); Alzheimer's disease (AD); Dynamic behavior; Bifurcation; Chaos

Notation

\begin{tabular}{|c|c|}
\hline$E_{N}$ & enzyme N \\
\hline$S_{N}$ & substrate N (catalyzed by enzyme N) \\
\hline$P_{N}$ & reaction product N (produced by $S_{N}$ catalyzed by $\left.E_{N}\right)$ \\
\hline$\left[H^{+}\right]$ & hydrogen ions concentration $\left(\mathrm{kmol} / \mathrm{m}^{3}\right.$ \\
\hline$\left[O H^{-}\right]$ & hydroxyle ions concentration $\left(\mathrm{kmol} / \mathrm{m}^{3}\right)$ \\
\hline$\left[S_{1}\right]$ & acetylcholine concentration $\left(\mathrm{kmol} / \mathrm{m}^{3}\right)$ \\
\hline$\left[S_{2}\right]$ & choline concentration $\left(\mathrm{kmol} / \mathrm{m}^{3}\right)$ \\
\hline$\left[S_{3}\right]$ & acetate concentration $\left(\mathrm{kmol} / \mathrm{m}^{3}\right)$ \\
\hline \hline$A C h E$ & concentration of acetylcholinesterase enzyme in compartment $2\left(\mathrm{~kg} \mathrm{enzyme} / \mathrm{m}^{3}\right)$ \\
\hline \hline$C h A T$ & concentration of cholineacetyl transferase in compartment $1\left(\mathrm{~kg} \mathrm{enzyme} / \mathrm{m}^{3}\right)$ \\
\hline$K_{s 1}, K_{i 1}, K_{h 1}$ & kinetic constants for the cholineacetyl transferase catalyzed reaction $\left(\mathrm{kmol} / \mathrm{m}^{3}\right)$ \\
\hline$K_{s 2}, K_{i 2}, K_{h 2}$ & kinetic constants for the coenzyme A catalyzed reaction $\left(\mathrm{kmol} / \mathrm{m}^{3}\right)$ \\
\hline
\end{tabular}




\begin{tabular}{|c|c|}
\hline$K_{s 3}$ & kinetic constants for the acetylcholinesterase catalyzed reaction $\left(\mathrm{kmol} / \mathrm{m}^{3}\right)$ \\
\hline$A_{M}$ & area of membrane separating compartments 1 and $2\left(\mathrm{~m}^{2}\right)$ \\
\hline$q$ & volumetric flow rate into compartment $1\left(\mathrm{~m}^{3} / \mathrm{s}\right)$ \\
\hline$R_{W(j)}$ & ate of water formation in compartment $\mathrm{j}\left(\mathrm{kmol} / \mathrm{m}^{3} \mathrm{~s}\right)$ \\
\hline$R_{(j)}$ & rate of reaction in compartment $\mathrm{j}\left(\mathrm{kmol} / \mathrm{m}^{3} \mathrm{~s}\right)$ \\
\hline $\mathrm{R}$ & recycle flow rate ratio \\
\hline$V_{(j)}$ & volume of compartment $\mathrm{j}\left(\mathrm{m}^{3}\right)$ \\
\hline $\mathrm{t}$ & time (s) \\
\hline$K_{W}$ & equilibrium constant for water $\left(\mathrm{kmol}^{2} / \mathrm{m}^{6}\right)$ \\
\hline$\alpha_{H^{+}}^{\prime}$ & membrane permeability for hydrogen ions $(\mathrm{m} / \mathrm{s})$ \\
\hline$\alpha_{O H^{-}}^{\prime}$ & membrane permeability for hydroxyl ions (m/s) \\
\hline$\alpha_{S_{1}}^{\prime}$ & membrane permeability for acetylcholine (m/s) \\
\hline$\alpha_{S_{2}}^{\prime}$ & membrane permeability for choline $(\mathrm{m} / \mathrm{s})$ \\
\hline$\alpha_{S_{2}}^{\prime}$ & membrane permeability for acetate $(\mathrm{m} / \mathrm{s})$ \\
\hline$\overline{C O A}$ & concentration of coenzyme A in compartment $1\left(\mathrm{~kg}\right.$ enzyme $\left./ \mathrm{m}^{3}\right)$ \\
\hline$V_{R}$ & $\mathrm{~V}_{1} / \mathrm{V}_{2}$ \\
\hline
\end{tabular}

Abbreviations: LMICs: Low-And Middle-Income Countries; IDF: International Diabetes Federation; NEHEP: National Eye Health Education Program; BDHS: Bangladesh Demographic and Health Survey; BIRDEM: Bangladesh Institute of Research and Rehabilitation in Diabetes, Endocrine and Metabolic Disorders; IPH: Institute of Public Health

\section{Introduction}

A complete neurocycle of Acetylcholine (ACh) involves a coupled two-enzyme system with the following two simultaneous events [1]:

Synthesis event: ACh is synthesized from choline and acetylCoA bio catalyzed by the enzyme choline acetyltransferase (ChAT) and immediately stored in small vesicular compartments closely attached to the cytoplasmic side of the presynaptic membranes $[1,2]$.

Degradation event: Once ACh has completed its activation duty, the synaptic cleft degradation begins removing the remaining ACh. This occurs when the ACh is consumed by the acetylcholinesterase (AChE) to form choline and acetic acid [3-5].

It has been found that the synthesis of ACh in the nerve endings is based on the preferential utilization of the choline which is supplied by the high affinity carrier from extra cellular fluid. Choline in the extra cellular fluid of the brain comes either directly from the free choline of the blood plasma, or from the brain cells, where it has been released from choline containing compounds $[4,5]$ found that using the steam pulse sequence (one of the main techniques commonly used for the diagnosis of imaged brain abnormalities), concentrations of choline in human brain frontal lobe white matter are found to be $1.9 \pm 0.5 \mu \mathrm{mol} / \mathrm{g}$ wet wt. In the thalamus, the concentrations are $2.0 \pm 0.4 \mathrm{~mol} / \mathrm{g}$ wet wt. Once in the extracellular space of the brain, choline can be taken up by all cells and used as a precursor of structural membrane phospholipids such as phosphatidylcholine and sphingomyelin and uniquely by cholinergic neurons for the conversion to ACh [6]. Phosphatidylcholine in these neurons also comprises a storage pool of choline, and the hydrolysis of phosphatidylcholine catalyzed by phospholipase Deliberates choline from this reservoir for the conversion to ACh by ChAT [7].

Several studies $[8,9]$ indicate that neurotransmitter external choline (modified) availability is an important factor regulating the dynamics of ACh metabolism and it appears that choline may be the rate-limiting substrate for ACh synthesis in vivo. Although a controversy exists [10] concerning the form of choline that is transported from the periphery to the brain, it is generally agreed that brain choline available for ACh synthesis is derived from sources outside the cholinergic neuron and include: (I) choline in the form of phospholipids, (2) free choline in plasma, and (3) choline generated from the hydrolysis of ACh.(Kewitz et al.,1975 Ansell and Spanner 1975) If a significant fraction of the choline used for ACh synthesis is derived from ACh hydrolysis, then under 
conditions of AChE inhibition, the size of this choline pool may be the limiting factor regulating the magnitude of the increase in ACh levels [2].

Several studies have suggested that acetate may affect the central nervous system (CNS) [Carmichael et al., (1991)]. The main entry point for acetate into metabolism in vertebrates is its conversion to acetyl-CoA by acetyl-CoA synthetase. The acetyl-CoA which is formed from acetate can be used for energy generation; on the other hand, acetyl-CoA is utilized in the brain's cholinergic neurons for ACh synthesis. It has been shown that extracellular acetate is accumulated by cholinergic nerve terminals for ACh formation and release [11].

There are some factors other than choline availability to ChAT that regulates ACh synthesis such as choline uptake to the presynaptic neuron and acetate to prevent expansion of the tissue ACh store [12-14] showed that the effect of AChE inhibition experimentally, on ACh labeling from acetate offers little support to the idea [15] that reuptake of acetate derived from hydrolyzed transmitter plays a role in maintaining ACh synthesis. In this way, acetate differs from the other product of transmitter hydrolysis, choline, which has been shown to be recaptured and used for ACh synthesis [15].

[16] investigated the neurocycle of the ACh utilizing a twocompartmentmodelwithAChEastheonlyenzyme.Theinvestigations unveiled complex static and dynamic behavior including bifurcation, instability, and chaos. [4] investigated a complete but simplified neurocycle for the ACh as a neurotransmitter in an AChE/ChAT system and found that complex dynamic bifurcations, hysteresis, multiplicity, period doubling and period halving, as well as period adding, and period subtracting dominated the dynamics of the system. [5] presented the formulation of a diffusion-reaction model utilizing available biokinetic information to simulate the in-vivo behavior of AChE and ChAT coupled enzymes system using a novel two-enzyme/two-compartment model to explore the bifurcation and chaotic behavior of this enzyme system simulating the ACh neurocycle in the brain. They carried out a detailed bifurcation analysis over a wide range of parameters in order to uncover some important information related to the phenomena occurring in the physiological experiments, like periodic stimulation of neural cells and non-regular functioning of ACh receptors. [5,16].

In this work we try to investigate the effect of choline, and AChE activity using two kinetic mechanisms one for the synthesis of ACh by the enzyme ChAT and the other for hydrolysis of ACh by the enzyme AChE. We attempt to analyze the synthesis of ACh at the level of single cells, rather than the whole nervous system and try to investigate the role of feed (external) choline and acetyl CoA on the ACh processes. The present work extends up on our earlier investigation [17-19]. Here we still employ a novel diffusionreaction model but improve upon our previous investigation by considering realistic kinetic schemes and data for ChAT synthesis reaction, and account for the recycle effects of choline.

\section{Proposed New Diffusion Reaction Two-Enzyme / Two Compartment Model}

The (AChE/ChAT) enzymes system inside the neural synaptic cleft can be schematically described in a simplified manner as shown in (Figure 1). The complete neurocycle of the ACh as a neurotransmitter is simulated as a simplified two-enzymes/twocompartment model. Each compartment is defined as a constant flow; constant volume, isothermal, continuous stirred tank reactor (CSTR) and the two compartments are separated by a permeable membrane. The behavior for a single synaptic vesicle is described by this simple two compartment model, assuming that all the events are homogeneous in all vesicles and using the proper dimensionless groups. From an enzyme kinetics point of view, the most general case is when the kinetics of both enzyme reactions has a double non-monotonic (dependence upon both state variables of substrate and hydrogen ions concentration). ACh is assumed to be synthesized in compartment 1 by ChAT due to the activation reaction as follows $[5,12]$ :
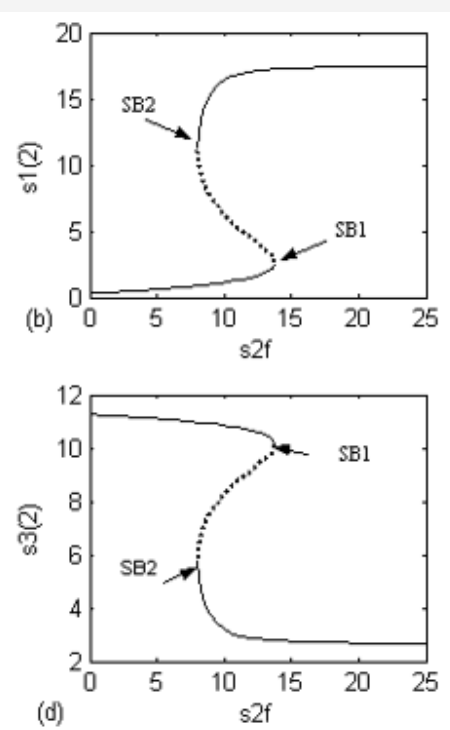

Figure 1: Schematic of synaptic neurons and cleft. 
$\mathrm{R}_{(1)}:$ Choline + Acetyl $\stackrel{\text { ChAT }}{\longrightarrow}$ CA ACh + CoA (1)

ACh is destroyed in compartment 2 by AChE by the degradation reaction as follows:

$$
\mathrm{R}_{(2)}: \mathrm{ACh}+\text { Water } \stackrel{C h A T}{\longrightarrow} \text { Choline }+ \text { Acetate }+\mathrm{H}^{+}
$$

Both reactions $R_{(1)}$ and $R_{(2)}$ are considered to be substrate inhibited and hydrogen ions affected. This leads to a non-monotonic dependence of the reaction rates on the substrates concentrations and $\mathrm{pH}$. The rates can be formulated by employing certain assumptions and basic biokinetics knowledge as explained in the following section. The details of the derivation are given in our previous work (Mustafa et al., 2008). The final dimensionless forms of the ordinary differential equations of the eight state variables are summarized in (Table 1). The model equations are in terms of eight state variables $s_{1(1)}, s_{1(2)}, s_{2(1)}, s_{2(2)}, s_{3(1)}$ and $s_{3(2)}$ and twentyfive parameters (Tables $2 \& 3$ ). All values of the parameters (with respective references) used in this investigation are given in (Table 1-3).

Table 1: Dimensionless forms of the ordinary differential equations of the eight state variables [17].

\begin{tabular}{|c|c|c|}
\hline Item & Compartment & Differential Equation \\
\hline \multirow{2}{*}{ Hydrogen protons } & 1 & $\frac{d h_{(1)}}{d T}=h_{f}-\gamma_{1}\left(\frac{1}{h_{f}}\right)-\alpha_{H}\left(h_{(1)}-h_{(2)}\right)+\alpha_{O H} \gamma_{1}\left(\frac{1}{h_{(1)}}-\frac{1}{h_{(2)}}\right)$ \\
\hline & 2 & $\frac{d h_{(2)}}{d T}=V_{R}\left(\alpha_{H}\left(h_{(1)}-h_{(2)}\right)-\alpha_{O H} \gamma_{1}\left(\frac{1}{h_{(1)}}-\frac{1}{h_{(2)}}\right)-\left(h_{(2)}-\frac{\gamma_{1}}{h_{(2)}}\right)+\frac{B_{2}}{k_{h 1}} r(2)\right)$ \\
\hline \multirow{2}{*}{ Acetylcholine } & 1 & $\frac{d s_{1(1)}}{d T}=s_{1 f}-\alpha_{s_{1}}\left(s_{1(1)}-s_{1(2)}\right)+\frac{B_{1} r(1)}{K_{s 1}}$ \\
\hline & 2 & $\frac{d s_{1(2)}}{d T}=V_{R}\left(\alpha_{S_{1}}\left(s_{1(1)}-s_{1(2)}\right)-s_{1(2)}-\frac{B_{2} r(2)}{K_{s 1}}\right)$ \\
\hline \multirow{2}{*}{ Choline } & 1 & $\frac{d s_{2(1)}}{d T}=s_{2 f}+R^{*} s_{2(2)}-\alpha_{S_{2}}\left(s_{2(1)}-s_{2(2)}\right)-\frac{B_{1}}{S_{2 \text { refernce }}} r(1)$ \\
\hline & 2 & $\frac{d s_{2(2)}}{d T}=V_{R}\left(\alpha_{S_{2}}\left(s_{2(1)}-s_{2(2)}\right)-(1+R) * s_{2(2)}+\frac{B_{2}}{S_{2 \text { reference }}} r(2)\right)$ \\
\hline \multirow{2}{*}{ Acetate } & 1 & $\frac{d s_{3(1)}}{d T}=s_{3 f}-\alpha_{S_{3}}\left(s_{3(1)}-s_{3(2)}\right)-\frac{B_{1}}{S_{3 \text { refernce }}} r(1)$ \\
\hline & 2 & $\frac{d s_{3(2)}}{d T}=V_{R}\left(\alpha_{S_{3}}\left(s_{3(1)}-s_{3(2)}\right)-s_{3(2)}+\frac{B_{2}}{S_{3 \text { refernce }}} r(2)\right)$ \\
\hline Rate of synthesis $\left(r_{1}\right)$ & 1 & $r_{(1)}=\frac{\theta_{1} s_{2(1)} s_{3(1)}}{\theta_{2} / h_{(1)}\left(h_{(1)}+1+\delta h_{(1)}^{2}\right)+\theta_{3} s_{3(1)}+\theta_{4} s_{2[1]}+\theta_{5} s_{2(1)} s_{3(1)}}$ \\
\hline Rate of hydrolysis $\left(\mathrm{r}_{2}\right)$ & 2 & $r_{(2)}=\frac{s_{1(2)}}{s_{1(2)}+1 / h_{(2)}\left(h_{(2)}+1+\delta h_{(2)}^{2}\right)+\alpha s_{1(2)}^{2}}$ \\
\hline
\end{tabular}

Table 2: Dimensionless state variables, parameters and other terms [17].

\begin{tabular}{|c|c|}
\hline$h_{j}=\frac{\left[H^{+}\right]_{j}}{K_{h 1}}$ & Dimensionless State Variables \\
\hline$S_{1 j}=\frac{\left[S_{1}\right]_{j}}{K_{s 1}}$ & Dimensionless hydrogen ion concentration in compartment $j$ \\
\hline$S_{2 j}=\frac{\left[S_{2}\right]_{(j)}}{\left[S_{2}\right]_{\text {reference }}}$ & Dimensionless acetylcholine concentration in compartment $j$ \\
\hline
\end{tabular}




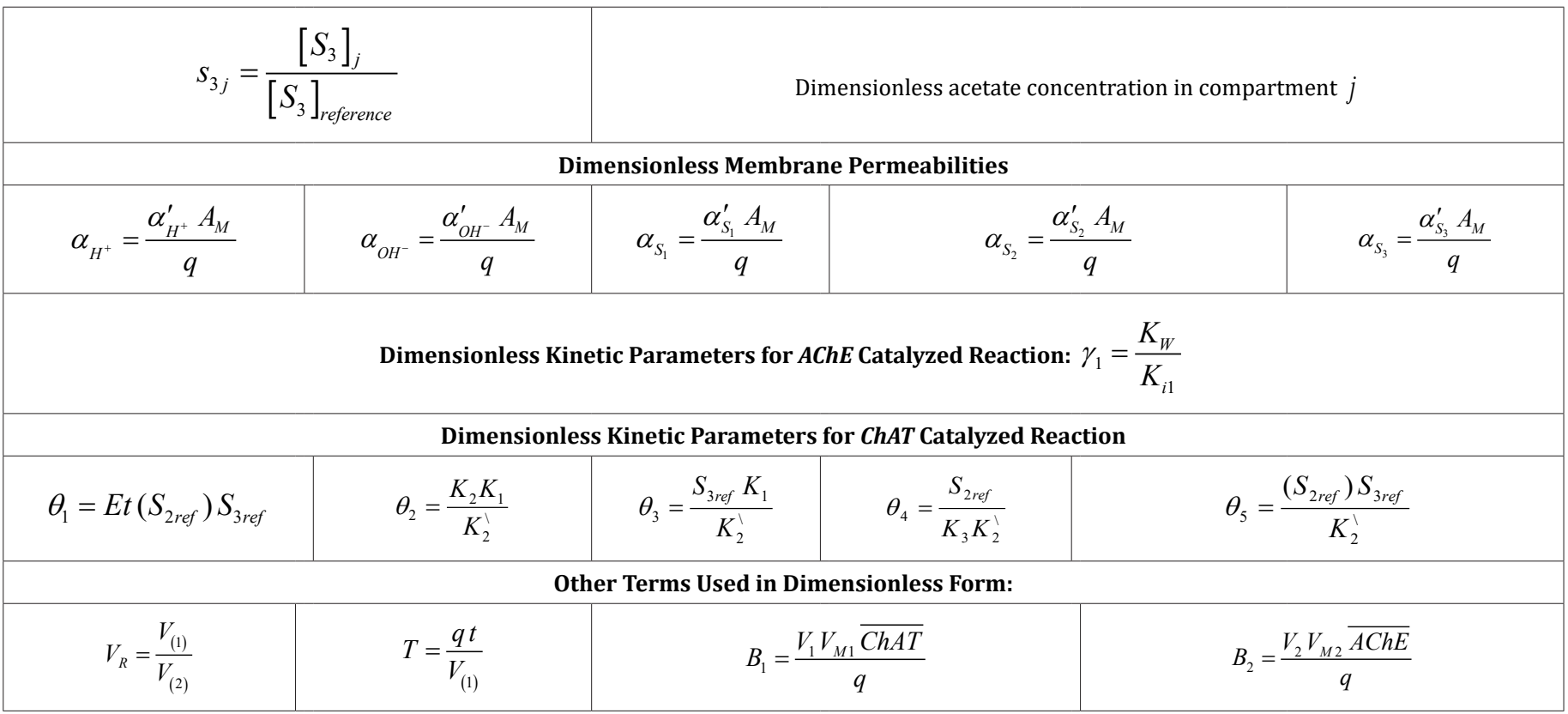

Table 3: Values of the kinetic parameters.

\begin{tabular}{|c|c|c|}
\hline Parameter & Value & Reference \\
\hline$\theta_{1}$ & $5.2(0.1)$ & Hersh \& Peet (1977); Mustafa et al., (2009) a, b \\
\hline$\theta_{2}$ & 12 & Hersh \& Peet (1977); Mustafa et al., (2009) a, b \\
\hline$\theta_{3}$ & 1000 & Hersh \& Peet (1977); Mustafa et al., (2009) a, b \\
\hline$\theta_{4}$ & 5 & Hersh \& Peet (1977); Mustafa et al., (2009) a, b \\
\hline$\theta_{5}$ & 1 & Hersh \& Peet (1977) \\
\hline$\alpha$ & 0.5 & Garhyan et al., (2006), Elnashaie et al., 1995; Ibrahim et al., 1997) \\
\hline$\delta$ & 1 & Garhyan et al., (2006), Elnashaie et al., 1995; Ibrahim et al., 1997) \\
\hline $\mathrm{K}_{\mathrm{a}}\left(\mathrm{k}_{\mathrm{h}}\right)$ & $1.066^{*} 10^{-6} \mathrm{kMole} / \mathrm{m}^{3}\left(\mu\right.$ Mole $\left./ \mathrm{mm}^{3}\right)$ & Shen and Larter (1994); Garhyan et al., (2006) \\
\hline $\mathrm{K}_{\mathrm{s} 1}$ & $5.033^{*} 10^{-7} \mathrm{kMole} / \mathrm{m}^{3}\left(\mu\right.$ Mole $\left./ \mathrm{mm}^{3}\right)$ & Radic and Taylor (2001) \\
\hline $\mathrm{S}_{\text {2ref }}$ & $1.0 \times 10^{-4} \mathrm{kMole} / \mathrm{m}^{3}\left(\mu\right.$ Mole $\left./ \mathrm{mm}^{3}\right)$ & Marriot (1994); Llcol et al., (2005); Guyton and Hall (2000); \\
\hline $\mathrm{S}_{3 \mathrm{ref}}$ & $1.0 \times 10^{-6} \mathrm{kMole} / \mathrm{m}^{3}\left(\mu\right.$ Mole $\left./ \mathrm{mm}^{3}\right)$ & Guyton Hall ( 2000) \\
\hline$B_{1}$ & $5.033 \times 10^{-5} \mathrm{kMole} / \mathrm{m}^{3}\left(\mu\right.$ Mole $\left./ \mathrm{mm}^{3}\right)$ & Bellier and Kimura (2007); Garhyan et al., (2006) \\
\hline$B_{2}$ & $5.033 \times 10^{-5} \mathrm{kMole} / \mathrm{m}^{3}\left(\mu\right.$ Mole $\left./ \mathrm{mm}^{3}\right)$ & Chuiko et al. (2003), Garhyan et al., (2006) \\
\hline$\alpha_{H^{+}}$ & 2.25 & Elnashaie et al., (1984) \\
\hline$\alpha_{O H^{-}}$ & 0.5 & Elnashaie et al., (1984) \\
\hline$\alpha_{H^{+}}$ & 1 & Elnashaie et al., (1984) \\
\hline$\alpha_{S_{1}}$ & 1 & Elnashaie et al., (1984) \\
\hline$\alpha_{S_{1}}$ & 1 & Elnashaie et al., (1984) \\
\hline$V_{R}$ & 1.2 & Elnashaie et al., (1984) \\
\hline$p H_{f}$ & 8.2 & Guyton (2000); Kaila and Ransom (1998) \\
\hline$s_{1 f}$ & 15 & Chuiko et al. (2003) \\
\hline$s_{2 f}$ & 1.15 & Chuiko et al. (2003) \\
\hline$s_{3 f}$ & 3.9 & Garhyan et al., (2006) \\
\hline$\gamma_{1}$ & 0.01 & Garhyan et al., (2006), Elnashaie et al., 1995; Ibrahim et al., 1997) \\
\hline $\mathrm{R}$ & 0.8 & Tucek (1978); Tucek (1987) \\
\hline
\end{tabular}




\section{Techniques and Numerical Tools}

The bifurcation diagrams are obtained using the software package XPP-AUT 5.0 (Ermentrout, 2002) which utilizes the wellknown continuation software AUT097 [15]. This package is able to perform both steady state and dynamic bifurcation analysis, including the determination of entire periodic solution branches using the efficient continuation techniques.

The classical time trace and phase plane for the dynamics are used. However, for high periodicity and chaotic attractors these techniques are not sufficient. Therefore, other presentation techniques based upon the plotting of discrete points of intersection (return points) between the trajectories and a hypersurface Poincaré surface, [13,20] are also employed [1]. These discrete points of intersection are taken such that the trajectories intersect the hyperplane transversally and cross it in the same direction. They are used to construct the Poincaré one parameter bifurcation diagram. A stiff solver with automatic step size to ensure accuracy is used for the numerical simulation of the periodic as well as the chaotic attractors. The program employed by [15] was used to plot the Poincare diagram.

\section{Physiological Values of the Parameters}

In order to compare the behavior of our model with experimental investigations (Weckler (1988), Morel (1976), Schwartz et al., (1975), Lynn Wecker et al., (1979)) [5], and with the models of prior researchers $[4,5]$ it is necessary to use the same range of the variables. An extensive literature review leads us to the following ranges:

- $\mathrm{pH}$ in the range of 6.95 to 7.15 was measured in human brain [21].

- $\quad \mathrm{pH}$ in the range of 6.95 to 7.35 was reported in a feline model, at which the cat is assessed as a model of experiments [15].

- ACh in a rat brain was found to be in the range of $\mathrm{kmol} / \mathrm{m}^{3}$. (Free ACh) to (total ACh) [2]. While, in guinea pig cerebral cortex the range was (free $\mathrm{ACh}$ ) to $\mathrm{kmol} / \mathrm{m}^{3}$. (total $\mathrm{ACh}$ ) $[2,12]$. These values represent content of free and total ACh in the brain.

- ACh concentration in human placenta was reported to be in the range of to $\mathrm{kmol} / \mathrm{m}^{3}$. (Wessler et al., 2001).

- ACh in the isolated rings of rat pulmonary artery was measured to be in the range of to $\mathrm{kmol} / \mathrm{m}^{3}$ produced concentration-dependent relaxations (Kysela and Torok, 1996).

- Choline concentration in mouse rat brain is about - kmol/ $\mathrm{m}^{3} \cdot[2,12]$ and [2].

- Choline concentration in human plasma was reported to be in the range of to $\mathrm{kmol} / \mathrm{m}^{3}$. (Chay and Rinzel, 1981).

The real concentration of $\mathrm{ACh}$ in cholinergic neurons of the brain is not known $[2,12]$. The content of ACh in the rat brain will be taken as $1.2 \times 10^{-5} \mathrm{kmol} / \mathrm{m}^{3}$ [2] On the assumption that the neurons represent $1 / 3$ of the weight of the brain ( The rest being attributable to glial cells and extracellular fluid), that the ACh is confined to cholinergic neurons, and that cholinergic neurons represent $10 \%$ of the total volume of all neurons, the concentration of ACh in the cholinergic neurons will be equal to $1.2 \times 10^{-5} \mathrm{kmol} / \mathrm{m}^{3} \times 30=36 \times 10^{\text {- }}$ ${ }^{5} \mathrm{kmol} / \mathrm{m}^{3}$. Despite the uncertainties associated with this estimate (the main being the proportion of cholinergic neurons in the total neuronal population of the brain), it is evident that, in the light of the present knowledge, the estimated equilibrium concentration of ACh $\left(12 \times 10^{-5} \mathrm{kmol} / \mathrm{m}^{3}\right)$ and the estimated concentration of ACh in cholinergic neurons $\left(36 \times 10^{-5} \mathrm{kmol} / \mathrm{m}^{3}\right)$ do not appear vastly different incompatible values. A higher concentration of ACh in presynaptic nerve endings might be achieved in two ways: by the accumulation of ACh in synaptic vesicles, and by higher concentration substrates in this part of neuron.

\section{Results and Discussion}

\section{Feed choline concentrations}

We investigate static and dynamic bifurcation due to the change of feed choline concentration. We studied the static bifurcation at higher value of feed ACh concentrations $s_{1 f}=15$ corresponding to $0.755 \times 10^{-5} \mathrm{kmol} / \mathrm{m}^{3}$ as a medium value in the range of ACh in rat brain given by Tucek 1978. and the dynamic bifurcation at s1f $=2.4$ corresponding to $0.12 \times 10^{-5} \mathrm{kmol} / \mathrm{m}^{3}$ which is the lowest value in the range given by Tucek 1978. The range given by Tucek 1978 is [ $0.12 \times 10^{-5}$ to $\left.1.77 \times 10^{-5}\right] \mathrm{kmol} / \mathrm{m}^{3}$.

\section{- Case (1): Static Bifurcation at $\mathbf{s 1 f}=15$ (corresponding to $0.755 \times 10^{-5} \mathrm{kmol} / \mathrm{m}^{3}$ )}

Figures 2 (a, b, c, d and e) show the bifurcation diagrams with as the bifurcation parameter for a very wide range of values using fixed values of and $\mathrm{h}_{1 \mathrm{f}}=0.0062682$ equivalent to $\mathrm{pH}=8.2$. Only a static bifurcation in the form of hysteresis-controlled system is found in this case. Figures 2(a, b, c, d and e) respectively show the static bifurcation through investigating the effect of changing the feed choline concentration $\left(\mathrm{s}_{2 \mathrm{f}}\right)$ on the ACh concentrations $\left(\mathrm{s}_{11}\right.$, and $\left.\mathrm{s}_{12}\right)$ in compartments 1 and 2, choline concentration in compartment 1 $\left(\mathrm{s}_{21}\right)$ and acetate concentration in compartment $2\left(\mathrm{~s}_{32}\right)$. The figures show that $s_{11}$, and $s_{12}$ are increasing with increasing s2f until certain value of $s_{2 \mathrm{f}}$ then $\mathrm{s}_{11}$, and $\mathrm{s}_{12}$ remain constant with further increase of $s_{2 f}$. This is compatible with the experimental results done by Tucek 1990 and Lefresne 1973 who indicated that the content of ACh increases until it reaches a certain limiting value and then remains stable when the choline substrate concentration increases. However; $s_{21}$ increases continuously as a function of $s_{2 f}$ If we investigated the effect of $s_{2 f}$ on $s_{22}, s_{22}$ will behave like $s_{21}$. The ACh concentrations synthesized in both compartments 1 and $2\left(s_{11}\right.$, $\mathrm{s}_{12}$ ) are increasing with high rate at, however; at high feed choline concentration corresponding to, ACh was synthesized less efficiently from the feed choline concentration which accumulated in nervous tissue. This is in agreement with the results obtained by Schwartz et al., (1975) who showed that at low concentration of feed choline, the fraction of the choline converted to ACh approached 60-75\%; 
this fraction decreased as the external choline concentrations were increased (Figure 2).

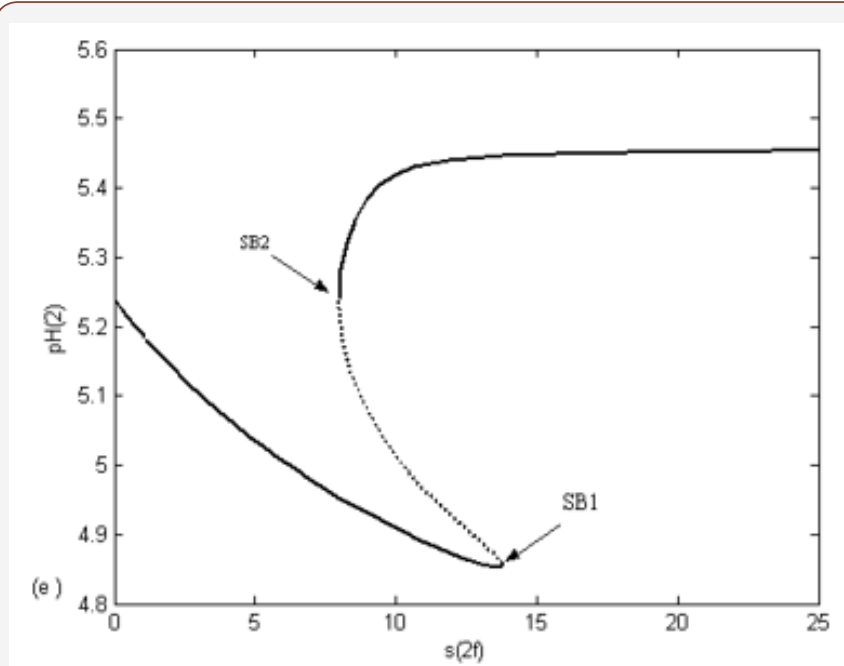

Figure 2: Bifurcation diagrams with choline feed concentration $S_{2 f}$ as the bifurcation parameter $\left(s_{1 f}=15\right)$ and the rest of data as shown in Table (3.2).

(a) Bifurcation diagram for ACh concentration in compartment $1\left(S_{11}\right)$, (b) Bifurcation diagram for $\mathrm{ACh}$ concentration in compartment $2\left(S_{12}\right)$. (c)Bifurcation diagram for choline concentration in compartment $1\left(s_{21}\right), \quad$ (d) Bifurcation diagram for acetate concentration in compartment $2\left(S_{32}\right)$. (e) Bifurcation diagram for $\mathrm{pH}$ in compartment $2\left(\mathrm{pH}_{2}\right)$.
From the constancy of ACh levels in both compartments in the presence of choline concentrations higher than the critical value, i.e. we can conclude that the release of ACh varied in parallel to the incorporation rate of the feed choline (s2f) to be catalyzed by the enzyme ChAT to produce ACh in compartment 1 . The released transmitter in compartment 2 is compensated by the ACh synthesized in compartment 1 . Therefore, the rate of ACh synthesis must be equal to the rate of transmitter release.

\section{- $\quad$ Case (2): Dynamic Bifurcation at $s_{1 \mathrm{f}}=2.4$}

Figures 3 (a, b, c, d and e) show the dynamic bifurcation diagrams using feed choline concentrations $\left(\mathrm{s}_{2 \mathrm{f}}\right)$ as the bifurcation parameter but with a different value of feed substrate concentrations which represent a very low feed ACh concentrations. The figures show different stages in the neurocycle for a narrow range of the bifurcation parameter $\left(0.6 \times 10^{-4} \leq s_{2 f} \leq 1.2 \times 10^{-4}\right) \mathrm{kmol} / \mathrm{m}^{3}$. It is clear that the system has rich dynamics phenomena at low concentration of $\mathrm{S}_{2 f}$ where the feed choline concentrations are too small to start the synthesis reaction catalyzed by ChAT (Figure 3).

Three main regions in the bifurcation diagram are observed, each one corresponding to a different form of qualitative behavior. There are two Hopf bifurcations (HBs). The first HB1 appears at $s_{2 f}=0.69$ and the other HB2 at $s_{2 f}=1.14085$.

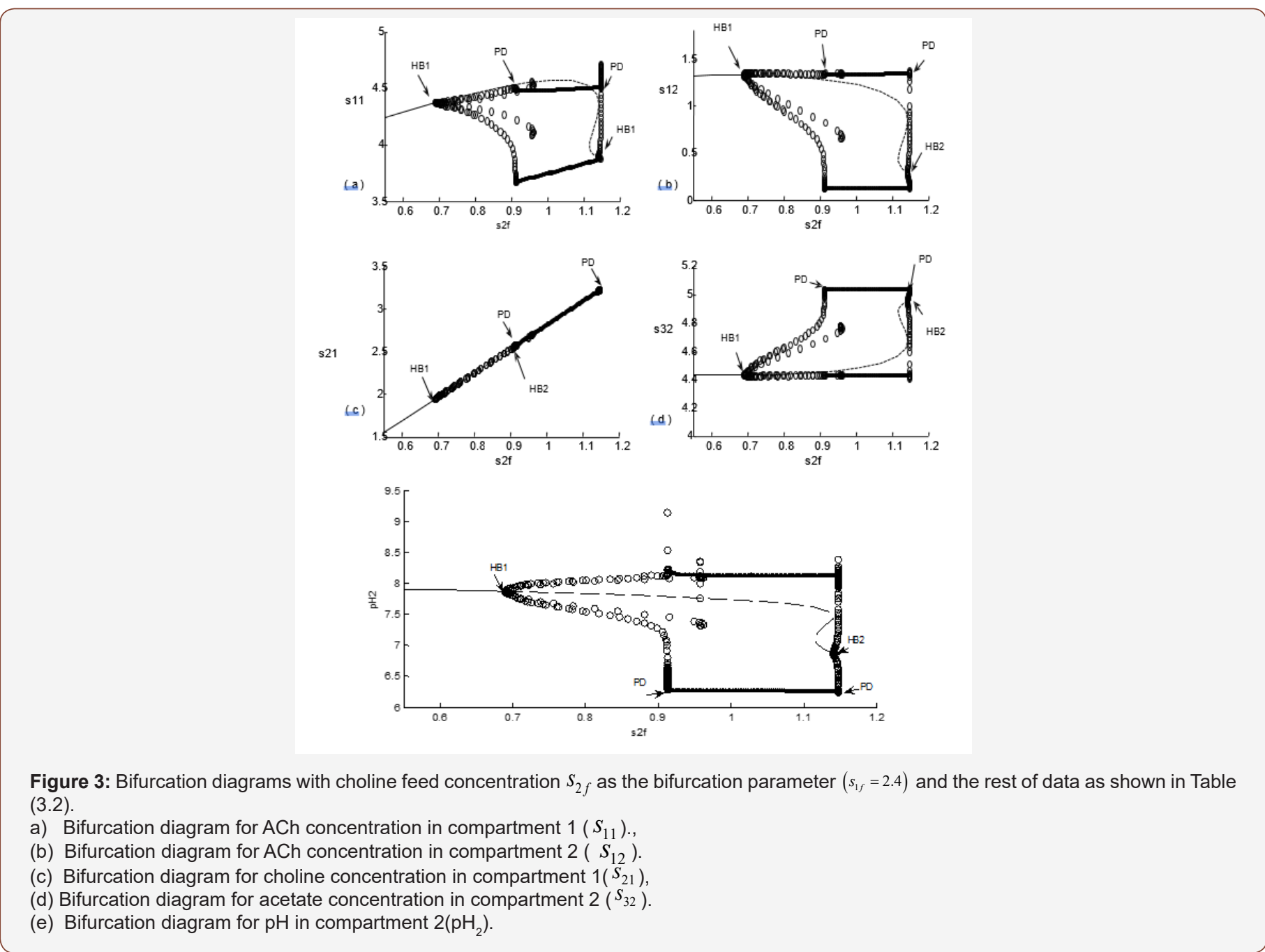


(a)

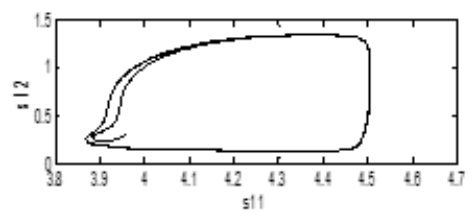

(c)

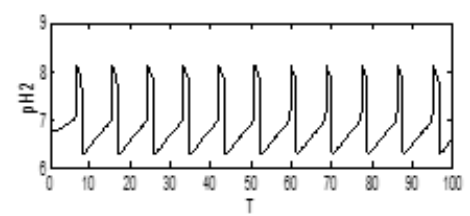

(e)

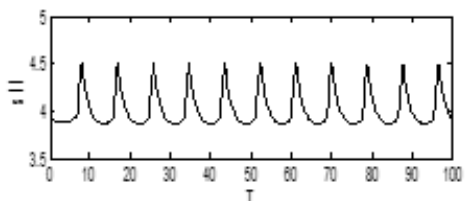

(b)
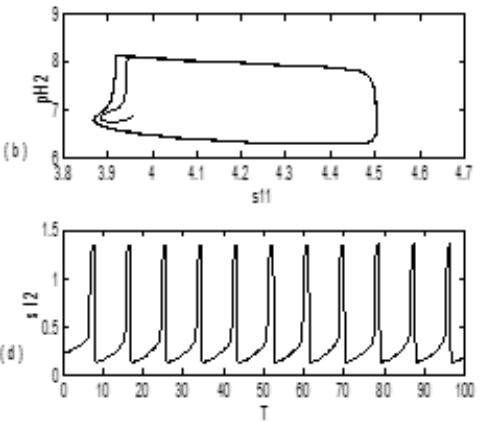

(i)

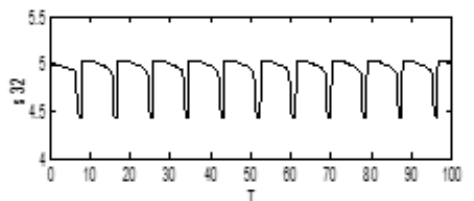

\begin{tabular}{|l|l|}
\hline \multicolumn{2}{|l|}{ Initial conditions } \\
\hline$\left.\underline{h_{(1}}\right)$ & 0.003796824 \\
\hline$h_{(2)}$ & 0.1405804 \\
\hline$s 11$ & 3.956 \\
\hline$s 12$ & 0.25 \\
\hline$s 21$ & 3.233 \\
\hline$s 22$ & 1.1606 \\
\hline$s 31$ & 8.2517318 \\
\hline$s 32$ & 4.9606 \\
\hline
\end{tabular}

Figure 4: Dynamic characteristics $s_{2 f}, s_{1 f}=2.4, s_{3 f}=3.9$, and $h_{f}$ for different initial conditions.

(a) Phase plane for ACh in compartment 2 vs. the ACh in compartment 1.

(b) Phase plane for $\mathrm{pH}$ in compartment 2 vs. the ACh in compartment 1

(c) Time traces of $\mathrm{pH}$ in compartment 2, (d) Time traces of ACh in compartment 2

(e) Time traces of ACh in compartment 1, (f) Time traces of acetate in compartment 2

Initial conditions $=[0.003796824 ; 0.1405804 ; 3.956 ; 0.3 ; 3.233 ; 1.1606 ; 8.2517318 ; 4.9606]$
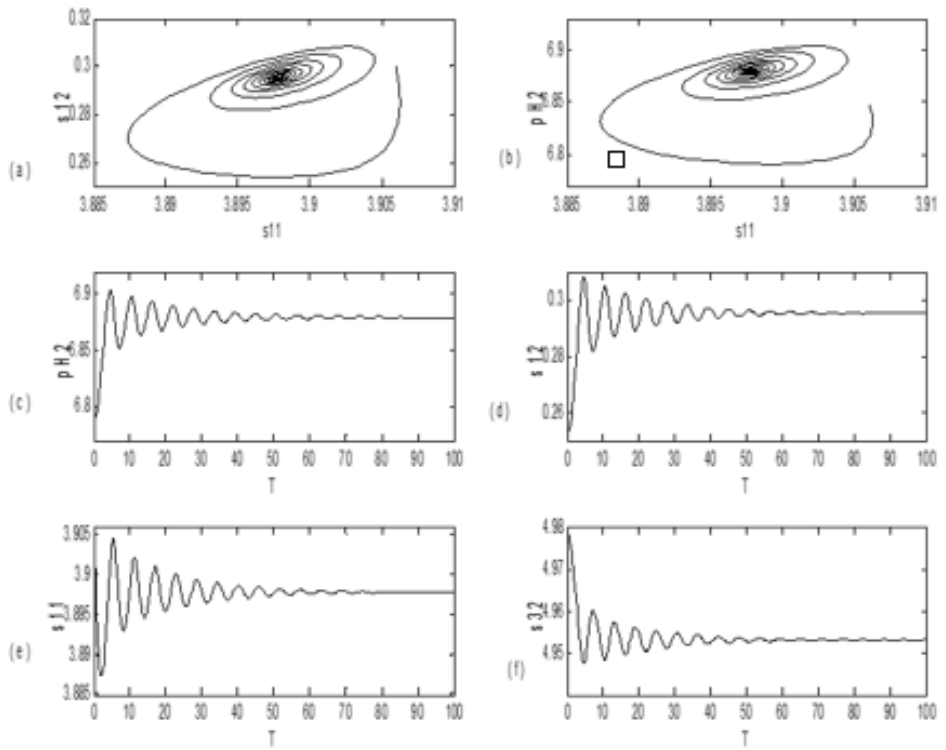

\begin{tabular}{|l|l|}
\hline \multicolumn{2}{|l|}{ Initial conditions } \\
\hline$h_{(1)}$ & 0.003796824 \\
\hline$h_{(2)}$ & 0.1405804 \\
\hline$s 11$ & 3.956 \\
\hline$s 12$ & 0.25 \\
\hline$s 21$ & 3.233 \\
\hline$s 22$ & 1.1606 \\
\hline$s 31$ & 8.2517318 \\
\hline$s 32$ & 4.9606 \\
\hline
\end{tabular}

Figure 5 
The physiological values correspond to a range of feed choline concentration between $11.41 \times 10^{-5}$ and $11.4676 \times 10^{-5}$. The $\mathrm{pH}$ in compartment $2\left(\mathrm{PH}_{2}\right)$ is inside the physiological expected range where it is between 6.75 and 8.2. This region with low choline concentration is thus characterized by the presence of bistability. The period doubling (PD) points occur at $\mathrm{s}_{2 \mathrm{f}}=0.913$ and $\mathrm{s}_{2 \mathrm{f}}=1.147$.
The period doubling is one of the routes leading to chaos. The first initial conditions (Figures 4) lead to a periodic attractor, while the second initial conditions (Figures 5) lead to a point attractor. In addition, when initial conditions are changed in certain range, chaos will appear as will be shown in (Figures 4-9).

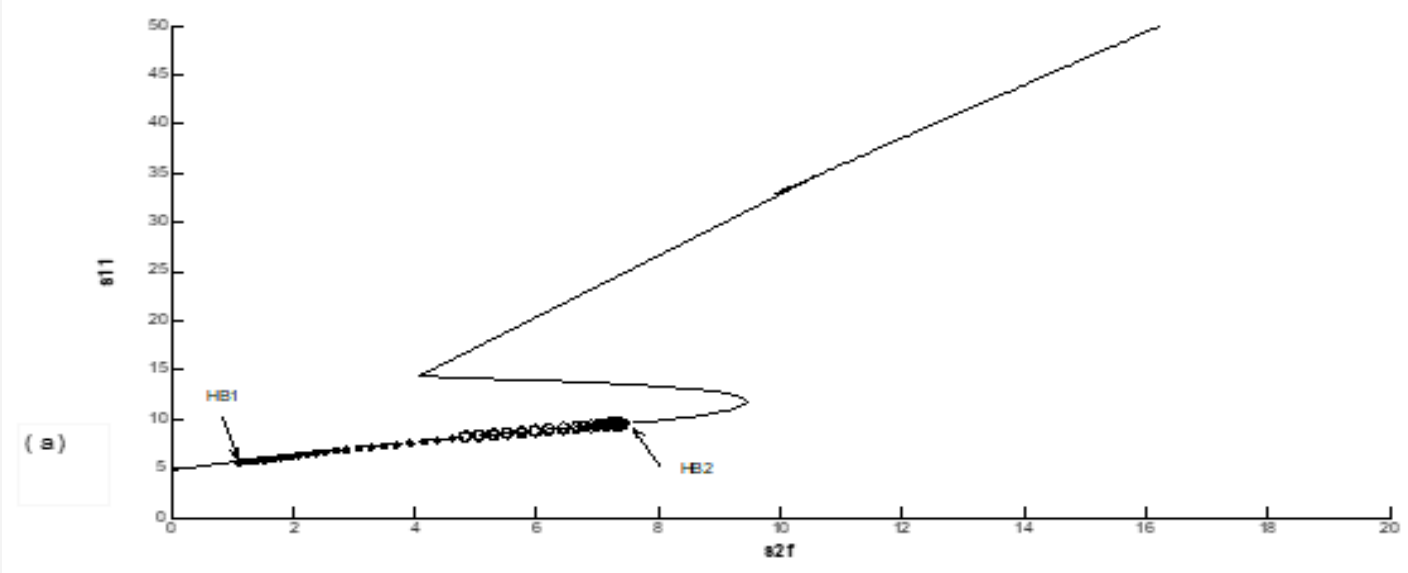

Figure 6

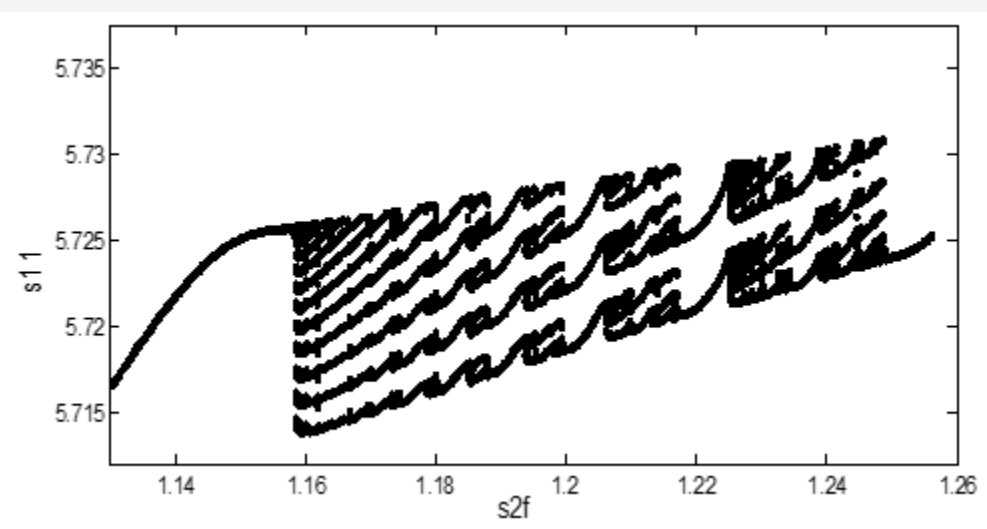

Figure 7: Poincare bifurcation diagram (Poincare plane is located at $s_{12}=0.3, s_{1 f}=4.5, s_{3 f}=2, h_{f}=0.002$ and the rest of parameters as shown Table (3).
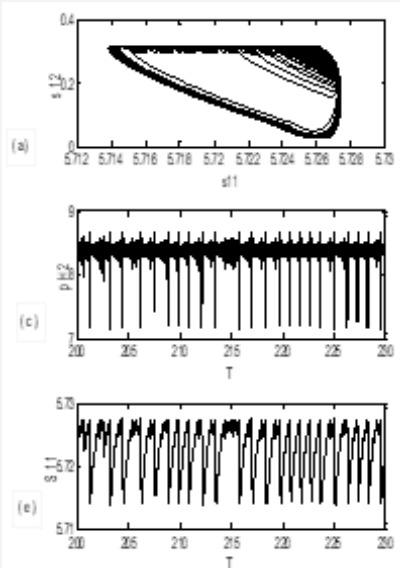

(b)
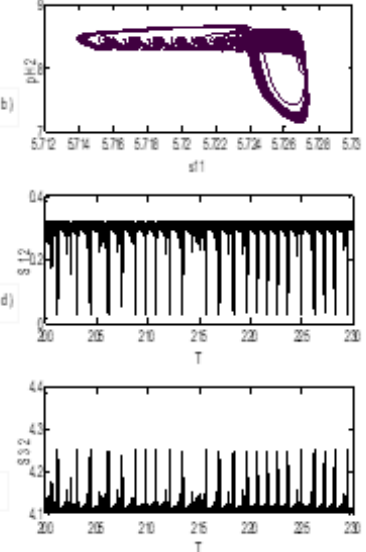

Figure 8: Dynamic characteristics at $s_{2 f}=1.15879999, s_{1 f}=4.5, s_{3 f}=2, h_{f}=0.002, B_{1}=0.0001, B_{2}=0.002$ and the rest of the system parameters as shown table 2 .

(a) Phase plane for ACh in compartment 2 vs. the ACh in compartment 1.

(b) Phase plane for $\mathrm{pH}$ in compartment 2 vs. the ACh in compartment 1

(c) Time traces of $\mathrm{pH}$ in compartment 2, (d) Time traces of ACh in compartment 2

(e) Time traces of ACh in compartment 1, (f) Time traces of acetate in compartment 2 
(a)

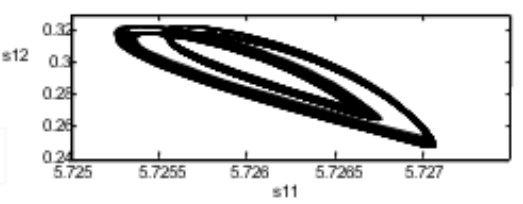

(c)
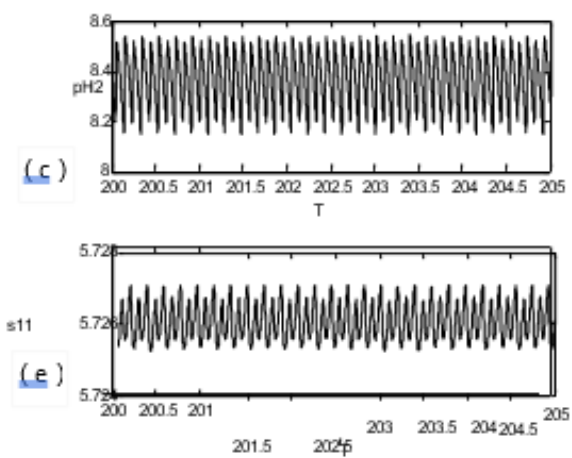
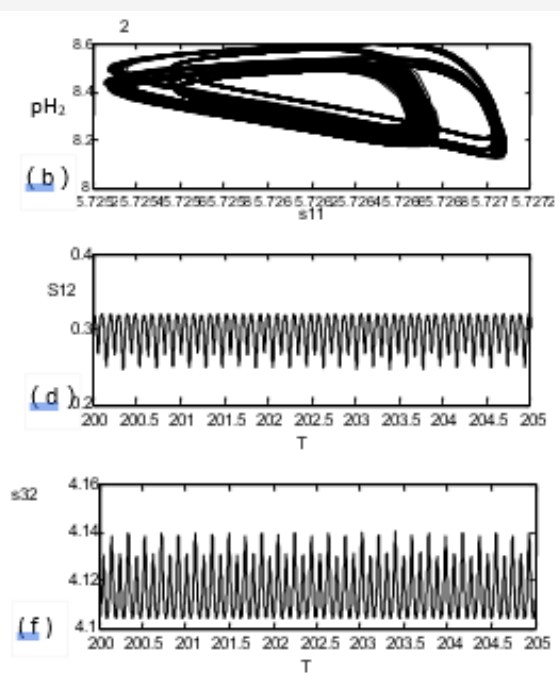

Figure 9: Dynamic characteristics at $s_{2 f}=1.158, s_{1 f}=4.5, s_{3 f}=2, h_{f}=0.002, B_{1}=0.0001, B_{2}=0.002$ and the rest of the system parameters as shown Table 3.
(a) Phase plane for ACh in compartment 2 vs. the ACh in compartment 1.
(b) Phase plane for $\mathrm{pH}$ in compartment 2 vs. the ACh in compartment 1
(c) Time traces of $\mathrm{pH}$ in compartment 2, (d) Time traces of ACh in compartment 2

\section{AChE enzyme activity}

AChE enzyme activity (B2) is chosen in order to gain some insight on the possible consequences of the change in the activity of the enzyme to hydrolyze the neurotransmitters. Wecker et al (1978) investigated the effect of AChE inhibition on the synthesis of acetylcholine in discrete brain regions in animals treated with the organophosphorus cholinesterase inhibitor paraoxon. They found that administration of paraoxon $(0.23 \mathrm{mg} / \mathrm{kg})$ inhibited acetylcholinesterase activity by nearly $90 \%$ in the striatum, hippocampus and cerebral cortex and acetylcholine levels increased to $149 \%, 124 \%$ and $152 \%$ of control values, respectively. Free choline levels were unaltered by paraoxon in the hippocampus and cerebral cortex, but significantly decreased in the striatum to $74 \%$ of control.

Imbalances in activity of AChE enzyme can be linked to devastating diseases like Alzheimer's and Parkinson's [5]. This bifurcation parameter $\left(B_{2}\right)$ incorporates the enzyme activity and three constants (AChE concentration in compartment 2, volume of compartment 2 and the flow rate): $B_{2}=\frac{V_{2} V_{M 2} \overline{A C h E}}{q}$ where $V_{M 2}$ is the maximum rate of ACh hydrolysis that contains kinetic constant that dominates the final reaction step.

Therefore, variation of the bifurcation parameter $B_{2}$ gives the effect of the variation of the enzymatic activity for the AChE catalyzed reaction. Two cases are analyzed for this particular bifurcation parameter. Case (1) which illustrates the important hysteresis (or short-term memory) phenomenon involved with the enzymatic activity (this phenomenon is extremely important for the possible link of this physiological system with the cholinergic diseases [4]. The second case discusses the dynamic bifurcation associated with the enzyme activity. These cases are discussed in detail below.

\section{A. Case (1): Static Hysteresis Behavior}

Figure 10 show the bifurcation diagrams with as the bifurcation parameter for a very wide range of values using fixed values of $s_{1 f}=50.0$ and $h_{1 f}=0.6268$. Only a static bifurcation in the form of hysteresis-controlled system is found in this case. As the value of the bifurcation parameter is decreased (equivalent to a decrease in AChE enzyme activity) while all other parameters are kept constant, different regions in the neurocycle are observed as shown in Figures 10 (a, b, c, d and e) as follows:

- Region 1: High enzyme activity in the region $\left(1.82 \times 10^{-4} \prec B_{2} \leq 3.5 \times 10^{-4}\right) \mathbf{~ k m o l} / \mathrm{m}^{3}$

In this region the system exhibits a unique stable steady state. In this region the $\mathrm{AChE}$ catalyzed reaction operates at its maximum capacity, consuming almost all the ACh in compartment (2) $\left(s_{1(2)}\right)$ . Figure 10(b) shows that the dimensionless $\left(s_{1(2)}\right)$ is kept in the range $s_{1(2)}=0.003379-2.94$. Figure 10 (a) shows that dimensionless $\left(s_{1(1)}\right)$ is kept in the range $s_{1(1)}=54.74-51.92$. Figures $10(\mathrm{c})$ and $10(d)$ show that $s_{21(1)}$ and $s_{3(2)}$ (products of AChE catalyzed reactions) have their maximum values in this region. The acetate in compartment (2) maximum value is $s_{3(2)}=28.9$, and the choline in compartment (1) maximum value is $s_{2(1)}=3.66074$. Figure. $10(\mathrm{e})$ shows that $\mathrm{pH}_{(2)}$ has its lowest value which is $\mathrm{pH}_{(2)}$ (maximum hydrogen concentration) because hydrogen ions are also produced in compartment 2 as the acetic acid disassociates into acetate and hydrogen ions.

This region corresponds to a very low value of ACh concentration in compartment(1) between and $\mathrm{kmol} / \mathrm{m}^{3}$, while in compartment (2) between $s_{2(1)}=3.66074$ and $2.6125 \times 10^{-5} \mathrm{kmol} / \mathrm{m}^{3}$ The $\mathrm{pH}$ in compartment 2 is also low ranging between 4.6 and 4.57 , while the choline concentration in compartment (1) is almost constant varying between (3.63433-3.66074) x 10-4 $\mathrm{kmol} / \mathrm{m}^{3}$ In comparison to the results of Mahecha Andres [4], ACh in compartment (1) and 
(2), and choline concentration in compartment (1) and acetate concentration in compartment (2), here, are higher than that in Mahecha Andres et al. This is because the choline recycle principle was not taken into consideration by Mahecha Andres et al., (2004) where the choline produced from the postsynaptic neuron is the main source for the choline required for ACh synthesis in the presynaptic neuron or compartment (1). In addition; the rate of synthesis of ACh which is proposed as shown in the Appendices is more efficient than used by Mahecha Andres et al, (2004).

$$
\text { - Region 2: }\left(0.899 \times 10^{-4} \leq B_{2} \leq 1.82 \times 10^{-4}\right) \mathrm{kmol} / \mathrm{m}^{3}
$$

As the enzyme activity is decreased to, a hysteresis phenomenon occurs, and a multiplicity of steady states is observed between the two static bifurcation points $\left(\mathrm{SB}_{1}\right.$ and $\left.\mathrm{SB}_{2}\right)$ in this region. This phenomenon is dominating the behavior of the system (it occurs for a wide range of the bifurcation parameter $B_{2}$ ). Hysteresis causes the state variables to be very sensitive in the neighborhood of the static bifurcation points. For example, in Figure 10(b) the dimensionless $\left(s_{1(2)}\right)$ jumps from $s_{1(2)}=2.94345$ to $s_{1(2)}=43.4$ with a slight decrease in enzyme activity near the static bifurcation point $\mathrm{SB}_{2}$ (Figure 10).

This region fits reasonably well to the expected physiological behavior. Figure 10(a) shows that $s_{1(1)}$ varies in the range 96.4 and 54.74 corresponding to $48.52 \times 10^{-6}$ and $27.55 \times 10^{-6} \mathrm{kmol} / \mathrm{m}^{3}$ while the dimensionless varies in the range 43.4 and 0.83 corresponding to $21.9 \times 10^{-6}$ and $0.418 \times 10^{-6} \mathrm{kmol} / \mathrm{m}^{3}$. Figure 10 (e) shows that $\mathrm{pH}(2)$ is out of the expected physiological range and is varying between 4.64 and 5.57. Figure 10 (c) shows that ${ }_{2}(1)$ is within the expected range between $3.264 \times 10^{-4}$ and $3.66 \times 10^{-4} \mathrm{kmol} / \mathrm{m}^{3}$. In the model of Mahecha Andres et al (2004) the hysteresis phenomena appeared in the range $\left(0.39766 \times 10^{-4} \leq B_{2} \leq 0.85 \times 10^{-4}\right) \mathrm{kmol} / \mathrm{m}^{3}$ which is smaller than our range. In addition, the ACh concentration in compartment (2) $\left(s_{1(2)}\right)$ in their model was in the range and $\mathrm{kmol} / \mathrm{m}^{3}$ which is closer to ours and the $\mathrm{pH}_{(2)}$ which is out of the expected physiological range and it was varying between 4.6 and 5.35 so it is also close to the range of ours. (a)

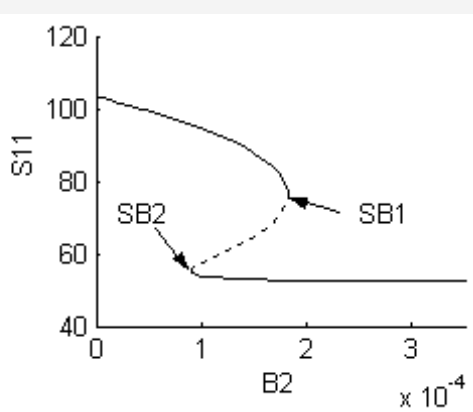

(c)

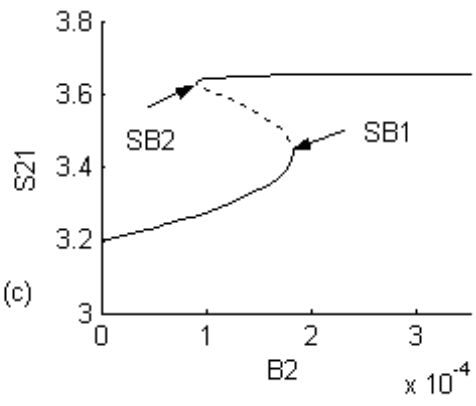

(b)

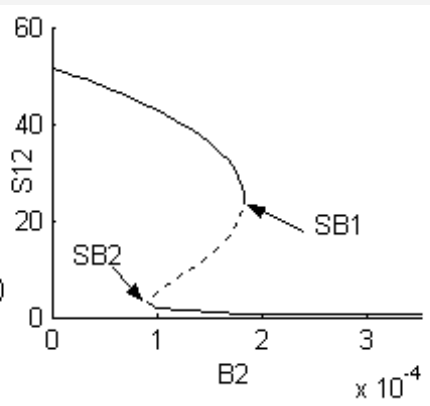

(d)

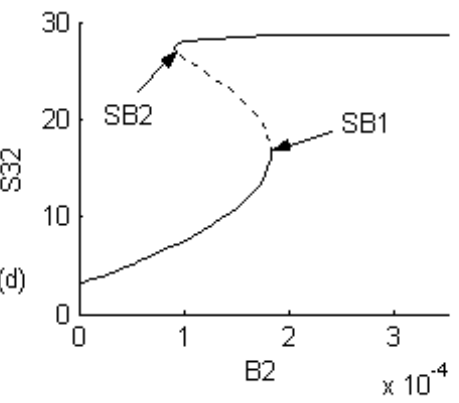

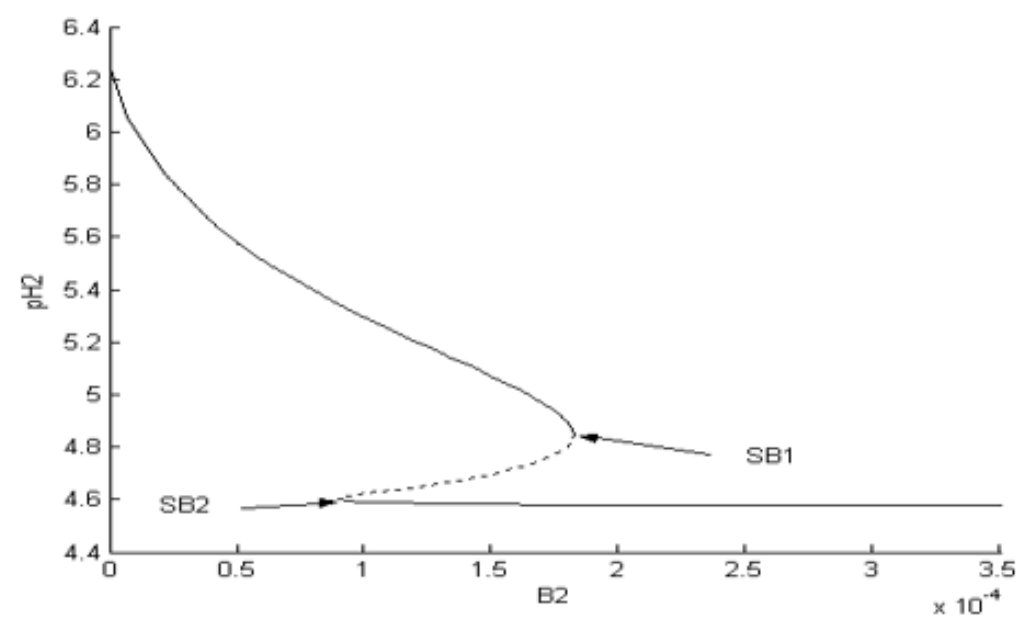

Figure 10 
- Region 3: Low enzyme activity in the region $\left(0 \leq B_{2} \leq 0.899 \times 10^{-4}\right) \mathbf{~ k m o l} / \mathbf{m}^{3}$.

In this region there is only a unique stable steady state. The values of the variables in this region are close to the physiological values and follow the expected biological behavior. Figure 10(a) shows that $S_{1(1)}$ varies between 96 and 104 corresponding to $48.32 \times 10^{-6}$ and $52.35 \times 10^{-6} \mathrm{kmol} / \mathrm{m}^{3}$. Figure $10(\mathrm{~b})$ shows that $s_{1(2)}$ varies between $2.18 \times 10^{-5}$ and $2.63176 \times 10^{-5} \mathrm{kmol} / \mathrm{m}^{3}$. Figure $10(\mathrm{e})$ shows that $\mathrm{pH}_{(2)}$ has a wide variation in the range 5.35 and 6.24. In comparison to Andres's model, $\mathrm{pH}$ is in the range 6 and 8.24 and the ACh in the range $2.1646 \times 10^{-5}$ and $2.506 \times 10^{-5} \mathrm{kmol} / \mathrm{m}^{3}$., which is close to our range

\section{B. Case (2): Dynamic Bifurcation}

Figure 11 shows the dynamic bifurcation diagrams using the enzyme activity parameter as the bifurcation parameter but with different values of feed substrate and hydrogen ions concentrations $\left(s_{1 f}=2.4, h_{1 f}=0.006268\right)$. For a wide range of the bifurcation parameter $\left(3.5 \times 10^{-5} \leq B_{2} \leq 5 \times 10^{-5} \mathrm{kmol} / \mathrm{m}^{3}\right)$. Figures $11(\mathrm{a}, \mathrm{b}, \mathrm{c}, \mathrm{d}$ and e) show a set of different stages in the neurocycle are recognized as follows:
- Region 1: Enzyme activity in the range $\left(4.99 \times 10^{-5} \leq B_{2} \leq 5.0 \times 10^{-5}\right) \mathrm{kmol} / \mathrm{m}^{3}$.

Figures 11(a, b, c, d and e) show that there is a unique stable steady state where AChE catalyzed reaction is operating at a high activity, thus consuming most of the ACh in compartment 2, $\left(s_{1(2)}\right)$. Figure $11(\mathrm{~b})$ show that $\left(s_{1(2)}\right)$ is in the range 0.280188 to 0.303586 corresponding to $0.141 \times 10^{-6}$ and $0.153 \times 10^{-6} \mathrm{kmol} /$ $\mathrm{m}^{3}$.while Figure 11(a) show that $\mathrm{s}_{1(1)}$ is between 3.897.and 3.91 corresponding to $1.961 \times 10^{-6}$ and $1.97 \times 10^{-6} \mathrm{kmol} / \mathrm{m}^{3}$. It is clear in Figure 11 (c and d) that the concentrations of choline and acetate (products of AChE catalyzed reaction) have high values in this region. The maximum dimensionless acetate concentration in compartment 2 is $s_{3(2)}=4.96067$ as shown in Figure $11(\mathrm{~d})$ and the maximum dimensionless choline concentration in compartment 1 is $s_{2(1)}=3.233$ as shown in Figure 11(c). In Figure 11(e) $\mathrm{pH}_{(2)}$ has its lowest value $\mathrm{pH}_{(2)}=6.84$ (maximum hydrogen ions concentration) in this region. On analyzing the physiological values $\mathrm{pH}_{(2)}$ does not agree with the physiological values varying between 7.14 and 7.16 (Figure 11(e)). Finally, in Figure 11(c) $s_{2(1)}$ is almost constant at in the range (0.280188-0.294428) $\times 10^{-4} \mathrm{kmol} / \mathrm{m}^{3}$ (Figure 11). (a)

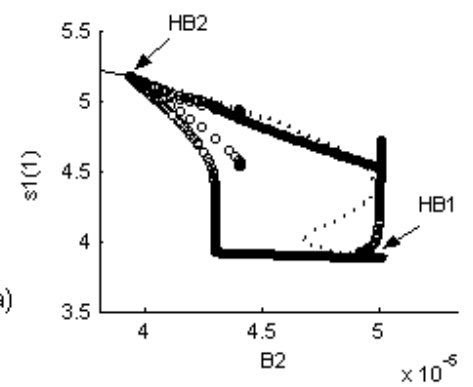

(c)

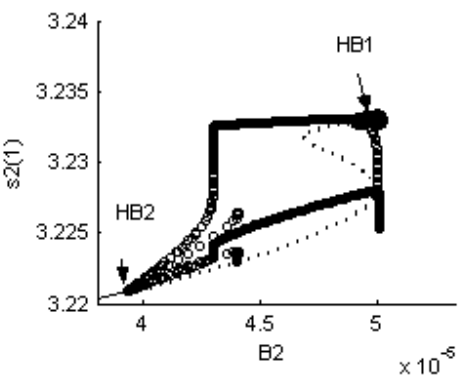

$\mathrm{HB} 2$

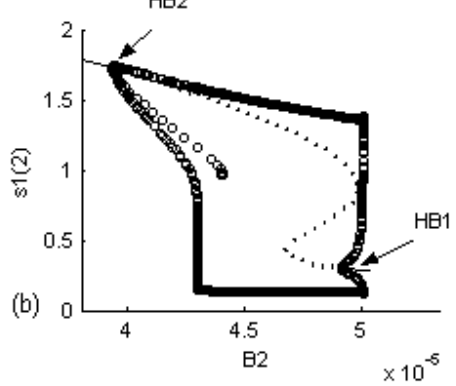

(d)

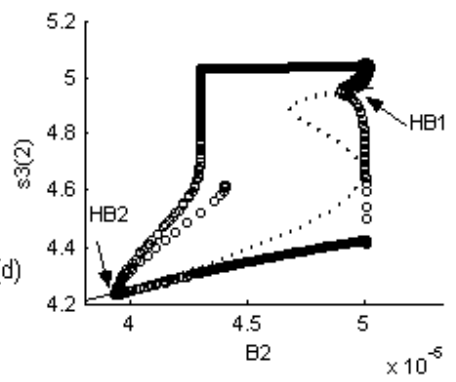

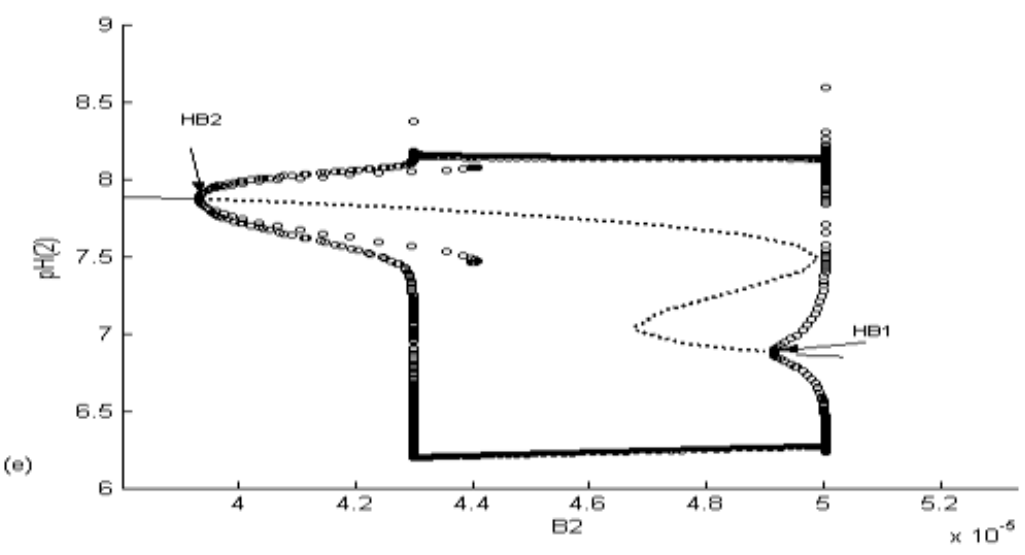

Figure 11 


\section{- Region 2: $\left(4.93 \times 10^{-5} \leq B_{2} \leq 4.99 \times 10^{-5}\right) \mathbf{~ k m o l} / \mathbf{m}^{3}$.}

In this region chaos may develop via the Feigenbaum (1980) Period doubling (PD) route which appears at $B_{2}=4.99 \times 10^{-5}$ as shown in Figs $11(\mathrm{a}, \mathrm{b}, \mathrm{c}, \mathrm{d}$ and e). In comparison to Mahecha Andres's model, Period doubling at $B_{2}=1.7784 \times 10^{-5}$ which is smaller than the previous range.

\section{- Region 3: $\left(4.91 \times 10^{-5} \leq B_{2} \leq 4.93 \times 10^{-5}\right) \mathrm{kmol} / \mathrm{m}^{3}$.}

As the enzyme activity decreases to $B_{2}=4.91 \times 10^{-5}$, Hopf bifurcation occurs $\left(\mathrm{HB}_{1}\right)$. Bistability behavior is observed where periodic and point attractors coexist with an unstable periodic orbit as the separatrix separating the domains of attraction of the periodic and point attractors. This type of bistability can lead to different types of attractors even at the same value of $B_{2}$ if the initial conditions are different. Figure 11(a) shows that $s_{1(1)}$ oscillates between 3.897 and 4.74 corresponding to $1.961 \times 10^{-6}$ and $2.39 \times 10^{-6} \mathrm{kmol} / \mathrm{m}^{3} \cdot \mathrm{pH}_{(2)}$ oscillates between 6.3 and 7.4 , which is a region near to the expected physiological $\mathrm{pH}$ values (Figure 11(e)). Figure 11(b) shows that $\mathrm{s}_{1(2)}$ oscillates between and kmol/ $\mathrm{m}^{3}$ corresponding to a low ACh concentration. Figure 11(c) shows that $s_{2(1)}$ is close to the expected physiological range with soft oscillations between and $\mathrm{kmol} / \mathrm{m}^{3}$.

- Region 4: $\left(4.26 \times 10^{-5} \leq B_{2} \leq 4.91 \times 10^{-5}\right) \mathrm{kmol} / \mathrm{m}^{3}$.

This region is dominated by unique stable periodic attractors showing sustained oscillations with similar qualitative behavior to the one discussed in Case I. This region corresponds to a range of $\mathrm{pH}_{(2)}$ between 6.15 and 8.2 (Figure 11(e)) which is close to the expected physiological $\mathrm{pH}$ values. In Figure $11(\mathrm{~b}) \mathrm{s}_{1(2)}$ oscillates between $5.033 \times 10^{-7}$ and $8.81 \times 10^{-7} \mathrm{kmol} / \mathrm{m}^{3}$ corresponding to low ACh concentration. The choline concentration in compartment 1 is in the expected physiological range with soft oscillations around $3.223 \times 10^{-4}$ and $3.233 \times 10^{-4} \mathrm{kmol} / \mathrm{m}_{3}$ as shown in Figure 11(c). The range of this region is smaller that of Andres which is $\left(1.78 \times 10^{-5} \leq B_{2} \leq 4.26 \times 10^{-5}\right) \mathrm{kmol} / \mathrm{m}^{3}$.

\section{- Region 5: $\left(3.93 \times 10^{-5} \leq B_{2} \leq 4.26 \times 10^{-5}\right) \mathbf{~ k m o l} / \mathbf{m}^{3}$.}

In this region, as the enzyme activity decreases to $B_{2}=3.93 \times 10^{-5}$ , the second Hopf bifurcation occurs $\left(\mathrm{HB}_{2}\right)$. Bistability behavior is observed where periodic and point attractors coexist with an unstable periodic orbit as the separatrix separating the domains of attraction of the periodic and point attractors. The second Hopf bifurcation occurs $\left(\mathrm{HB}_{2}\right)$ in Mahecha Andres is at $B_{2}=1.73 \times 10^{-5}$.

- Region 6: $\left(0 \leq B_{2} \leq 3.93 \times 10^{-5}\right) \mathbf{~ k m o l} / \mathbf{m}^{3}$.

In this region there is a unique stable steady state (point attractor). The physiological values in this region correspond to range of $\mathrm{pH}_{(2)}$ from 7.87 to 8.2 which is near to the range of Mahecha Andres results where $\mathrm{pH}_{(2)}$ is between 7.83 and 8.23 (Figure 11(e)). In Figure 11(a), $\mathrm{s}_{1(1)}$ reaches the maximum value at very low values of $\mathrm{B}_{2}$, where $\mathrm{s}_{1(1)}=6.62$ corresponding to $\left(3.33 \times 10^{-6} \mathrm{kmol} / \mathrm{m}^{3}\right)$ which is the highest value in Figures 11(a and b).Figure 11(b) shows that $\mathrm{s}_{1(2)}$ reaches its maximum value $\left(1.66 \times 10^{-6} \mathrm{kmol} / \mathrm{m}^{3}\right)$ as the reaction that consumes it almost stops in this region. However, in the model of Mahecha Andres et al., the maximum value of $s_{1(2)}$ reaches its $\left(1.258 \times 10^{-6} \mathrm{kmol} / \mathrm{m}_{3}\right)$. In Figure $11(\mathrm{c}) \mathrm{s}_{2(1)}$ reaches its $\mathrm{s}$ its lowest value $\left(3.275 \times 10^{-4} \mathrm{kmol} / \mathrm{m}^{3}\right)$ as the reaction that produces it almost stops. This value of $\mathrm{s}_{2(1)}$ is higher than that in the model of Mahecha Andres et al., (2004), as discussed before because the choline consumed in the presynaptic neuron which is compensated by recycling the choline produced by hydrolysis reactions was not taken into consideration by Mahecha Andres. Therefore, the range of the dynamics of the results of Mahecha Andres et al (2004) is larger than ours where $\mathrm{HB}_{1}$ and $\mathrm{HB}_{2}$ appear in the results of Mahecha Andres in the range $\left(1.82 \times 10^{-5} \leq B_{2} \leq 4.43 \times 10^{-5}\right)(\mathrm{kmol} /$ $\mathrm{m}^{3}$ ) and $\mathrm{HB}_{1}$ and $\mathrm{HB}_{2}$ appear at $\mathrm{B}_{2}=1.82 \times 10^{-5}$, and $4.43 \times 10^{-5}$ respectively; however our model show that $\mathrm{HB}_{1}$ and $\mathrm{HB}_{2}$ appear in the range $\left(3.93 \times 10^{-5} \leq B_{2} \leq 4.91 \times 10^{-5}\right)$.

\section{Summary and Conclusion}

In this work, the effects of both feed choline and acetate concentrations on a coupled AChE/ChAT enzymes system have been investigated considering the choline reuptake into the presynaptic neuron. It has been found that as the feed choline concentrations increase, ACh levels in both compartments increase gradually until $\left(s_{2 f}=25.6\right)$ where ACh is synthesized less efficiently when $\left(s_{2 f} \geq 25.6\right)$. So that the release of ACh in compartment 2 varies in parallel to the incorporation of the choline in compartment 1 to produce ACh. The released transmitter can be compensated by the ACh synthesized in compartment $1\left(\mathrm{~s}_{11}\right)$. Therefore, the rate of ACh synthesis must be equal to the rate of transmitter release. This is in agreement with the results obtained by Schwartz et al., (1975).

At low concentrations of the feed choline concentrations, it has been found that the system exhibits complex dynamics bifurcation including chaotic behavior via a period doubling sequence in the range ( $\left.1.14085 \leq s_{2 f} \leq 1.14676\right)$. A bistability behavior is observed where periodic and point attractors coexist with an unstable periodic orbit as the separatrix separating the domains of attraction of the periodic and point attractors. This bistability leads to the condition, that at the same value of $s_{2 f}$ slightly different initial conditions lead to different types of attractors. Both periodic orbits and steady stationery states are co-existing together as shown in Figures 4 and 5. Then periodic orbits cease to exist, at a PLP bifurcation, and the system recovers its stability. The biochemical interpretation for the unstable waves in Figures 4 and 6 is that they occur as a consequence of the competition between diffusion and enzyme reaction(s). It can be concluded that the uptake of choline into the nervous system at low external concentrations plays a determining role in synthesis of the transmitter. In addition, ACh was synthesized considerably less efficiently from the excess choline which accumulated in nervous tissue at external concentrations greater than about $30 * 10^{-4} \mathrm{kmole} / \mathrm{m}^{3}$.

The results are analyzed based on the physiological values in order to simulate the ACh hydrolysis in the synaptic cleft in compartment 2 . The system in case of external disturbances such as the sudden change of feed choline concentration to the presynaptic neurons could be affected by the hysteresis with a sudden 
increase in ACh concentration in both compartments (especially in compartment 2 where ACh concentration increases 6 folds from $\mathrm{c}$ to $9.1 \times 10^{-6} \mathrm{kmol} / \mathrm{m}^{3}$ near $\mathrm{S}_{\mathrm{B} 1}$ as shown in Figure $2(\mathrm{~b})$ with a small variation in the input conditions thus simulating the sudden neural transmission, this means that the gradual synthesis of ACh is not satisfactory for rapid synthesis of ACh to compensate for the released amount and that a simple regulatory mechanism of linear feedback of the ACh level can accomplish the ACh replenishment for maintenance of the transmission activity. It would follow from dynamic analysis and the importance activity of enzymes that in the presynaptic terminal, a feedback mechanism of neurotransmitter levels operates as a basic control apparatus to regulate the synthesis and supply of transmitters in response to the release.

It has been found that the feed acetate concentrations have less effect on ACh concentrations in both compartments in comparison to the feed choline concentrations. The system is rich with the dynamics at low concentration of $s_{3 f}$ where the feed acetate concentrations are too small to start the synthesis reaction catalyzed by ChAT. These results are in agreement with the experimental results of Kwok et al., (1982) who showed that increased acetylCoA delivery alone is not enough for optimal AsCh synthesis, and it is possible that choline delivery is limiting to transmitter synthesis. Finally, it can be concluded that feed choline is the most important substrate to ACh synthesis.

Many state variables correspond to the physiological expected values in some regions. This can direct future experimental research in order to use this novel eight-dimensional model for simulating real physiological behavior. Availability of good experimental data for human brain in future can help to greatly improve this model for deeper understanding of the physiological behavior and can help in planning better brain experiments and linking the complex behavior investigated in this paper to the cholinergic disorders and diseases such as AD and PD.

\section{Acknowledgement}

None.

\section{Conflict of Interest}

No conflict of interest.

\section{References}

1. Guyton CA, Hall JE (2000) Textbook of Medical Physiology. tenth (ed) WB Saunders Company: Amsterdam.

2. Tucek S (1978) Acetylcholine Synthesis in Neurons; Champan \&hall, London.

3. Tucek S (1983) The synthesis of acetylcholine, in Handbook of Neurochemistry.

4. Mahecha Andres - Botero, Parag Garhyan, Elnashaie SSEH, (2004) Bifurcation and chaotic of a coupled acetylcholinesterase/choline acetyltransferase diffusion-reaction enzymes system. Chemical Engineering Science 59(3): 581-597.

5. Garhyan Parag, Mahecha A Botero, Elnashaie SSEH (2006) Complex Bifurcation/ Chaotic Behavior of Acetyl cholinesterase and cholineacetyltransferase Enzymes system. Mathematical and computer Modeling 30(9): 824-853.

6. Blusztajn JK, Wurtman RJ (1983) Choline and cholinergic neurons.
Science Science 221(4611): $614-620$.

7. Lee H-C, Fellenz-Maloney M-P, Liscovitch M, Blusztajn JK (1993) Phospholipase D-catalyzed hydrolysis of phosphatidylcholine provides the choline precursor for acetylcholine synthesis in a human neuronal cell line. Proceedings of the Natural Academy of Sciences USA 90(21): 10086-10090.

8. Sykova E (2004) Extrasynaptic volume transmission and diffusion parameters of the extracellular space. Neuroscience 129(4): 861-876.

9. Denton JS, McCann FV, Leiter JC (2007) $\mathrm{CO}_{2}$ chemosensitivity in /Helix aspersa/: Three $\mathrm{K}^{+}$currents mediate $\mathrm{pH}$-sensitive neuronal activity. Am J Physiology Cell 292(1): C292-C304.

10. Takeshi Fujii, Watanabe Y, Fujimoto K, Kawashima K (2003) Expression of acetylcholine in lymphocytes and modulation of an independent lymphocytic cholinergic activity by immunological stimulation. Biogenic amines 17(4-6): 373-386

11. Chesler M (2003) Regulation and Modulation of $\mathrm{pH}$ in the Brain. Physiological Reviews 83(4): 1183-1221.

12. Tucek $S$ (1990) The synthesis of acetylcholine: twenty years of progress. Progress in Brain Research 84: 467-477.

13. Cooper Jack R (1994) Unsolved Problems in the Cholinergic Nervous System. Journal of Neurochemistry 63(2): 395-399.

14. Hindmarsh JL, Rose RM, (1982) A model of the nerve impulse using two first-order differential equations. Nature 296(5853): 162-164.

15. Ibrahim G, Elnashaie SSEH (1997) Hyperchaos in acetylcholinesterase enzyme systems. Chaos, Solitons \& Fractals. 8: 1977.

16. Elnashaie SSEH, Ibrahim G, Teymour FA (1995) Chaotic behavior of an acetyl cholinesterase enzyme system. Chaos Solitons \& Fractals 5(6): 933.

17. Mustafab IH, Elkamel A, Ibrahim G, Elnashaie SSEH, Chen P, (2009) Effect of Choline and Acetate Substrates on Bifurcation and Chaotic Behavior of Acetylcholine Neurocycle and Alzheimer's and Parkinson's Diseases. Journal of chemical engineering science 64(9): 2096-2112.

18. Mustafac IH, Ibrahim G, Elkamel A, Chen P, Elnashaie SSEH (2011) Effect of Cholineacetyl transferase Activity and Choline Recycle Ratio. Journal of Chemical Engineering Science.

19. Mustafad I, Elkamel A, Lohi A, Chen P, Elnashaie SSEH, et al. (2012) Application of continuation method and bifurcation for the acetylcholine neurocycle considering partial dissociation of acetic acid. Computers \& Chemical Engineering 46(15): 78-93

20. Bartolini M, Cavrini V, Andrisano O (2005) Batchwise covalent immobilization of human acetylcholinesterase: Kinetic and inhibition spectrophotometric studies. Analytical Biochemistry 342(1): 163-166

21. Ballivet M, Alliod C, Bertrand S, Bertrand D (1996) Nicotinic ACh receptors in the nematode Caenorhabditis elegans. Journal of Molecular Biology 258(2): 261-269.

22. Alzheimer A (1906) Uber a peculiar severe disease process of the cerebral cortex. Neurological Centralblatt (Lecture presented at the 37 th meeting of the southwest German psychiatrists in Tubingen) 23: 1129.

23. Awad A, Fgaier H, Mustafa I, Elkamel A, Elnashaie S, (2019) Pharmacokinetic/ Pharmacodynamic modeling and simulation of the effect of medications on $\beta$-amyloid aggregates and cholinergic neurocycle, Computers \& Chemical Engineering 126: 231-240

24. Bielarczyk H, Szutowicz A (1989) Evidence for the regulatory function of synaptoplasmic acetyl- CoA in ACh synthesis in nerve endings. Biochemical journal 262: 377-380.

25. Birks RI, Worsley KJ, Birks RI (1985) Activation of ACh synthesis in cat sympathetic Ganglia: dependence on external choline and sodiumpump rate. journal of Physiology 367: 401-417

26. Brown Jon T, Kate L, Weatherall, Laura R, Corria, et al. (2010) Vesicular release of glutamate utilizes the proton gradient between the vesicle and synaptic cleft. Frontiers in Synaptic Neuroscience 2: (15).

27. Damsma G, Lammerts van Bueren D, Westerink I BHC, Horn A (1987) Determination of $\mathrm{ACh}$ and choline femtomole range by means of 
HPLC, a post-column enzyme reactor, and electrochemical detection. Chromatographia. 24: 827-831.

28. Elnashaie SSEH, El-Rifai MA, Ibrahim G (1983) The effect of hydrogen ion production on the steady-state multiplicity of substrate inhibited enzymatic reactions. II. Transient behavior. Applied Biochemistry and Biotechnology 8(6): 467.

29. Elnashaie SSE, Uhlig F, Affane Cb (2007) Numerical techniques for chemical and biological engineers using MATLAB: a simple bifurcation approach, Springer. New York.

30. Feigenbaum ML (1980) Universal behavior in nonlinear systems. Los Alamos Science 1: 4-36.

31. Fgaier H, Mustafa IHI, Awad AAR, Elkamel A, (2015) Modeling the interaction between $\beta$-amyloid aggregates and choline acetyltransferase activity and its relationship with cholinergic dysfunction through twoenzyme/two-compartment model. Computational and mathematical methods in medicine.

32. Glenn Wetzel, Joan Heller Brown (1983) Relationship between Choline uptake ACh synthesis and ACh release in isolated rat atria. Journal of pharmacology and Experimental Therapeutics 226(2): 343-348.

33. Hindmarsh JL, Rose RM, (1984) Model of neuronal bursting using three coupled first order differential equations, Proceedings of the Royal Society of London. Series B Biological Sciences 221(1222): 87-102.
34. Holden AV, Fan YS, (1992a) From simple to simple bursting oscillatory behavior via chaos in the Rose- Hindmarsh model for neuronal activity. Chaos Solitons \& Fractals 2(3): 221-236.

35. Holden AV, Fan YS (1992b) From simple to complex oscillatory behavior via intermittent chaos in the Rose-Hindmarsh model for neuronal activity. Chaos Solitons \& Fractals 2(4): 349-369.

36. Holden AV, Fan YS (1992c) Crisis-induced chaos in the Rose-Hindmarsh model for neuronal activity. Chaos, Solitons \& Fractals 2(6): 583-595.

37. Ibrahim G, Saleh O, Mustafa IH, El Ahwany AH, Elnashaie SSEH (2010) Modeling Periodic and Aperiodic Behavior of Acetylcholine Hydrolysis. International Review of Chemical Engineering (IRECHE) 2(6): 647-666.

38. Ismail H Ulus, Richard J Wurtman, Charlotte Mauron, Blusztajn JK (1989) Choline increases acetylcholine release and protects against the stimulation-induced decrease in phosphatide levels within membranes of rat corpus striatum. Brain Research 484(1-2): 217-227.

39. Mustafaa IH, Ibrahim G, Elkamel A, Elnashaie SSEH, Chen P (2009) Nonlinear Feedback Modeling and Bifurcation of the Acetylcholine Neurocycle and its Relation to Alzheimer's and Parkinson's Diseases. Journal of chemical engineering science 64(1): 69-90. 